\title{
The Role of Advance Technologies in Motivated Learning: Case Study of Saudi Learners in Universities
}

\author{
Faheem Abass ${ }^{*}$, N. Abas ${ }^{2}$ \\ ${ }^{1}$ MAWYAH ABDULLAH AL-BKHEET-EST, Al-Ahsa- Al Hofuf, Saudi Arab \\ ${ }^{2}$ Department of Electrical Engineering, University of Gujrat, Hafiz Hayat
}

\begin{abstract}
The goal of information technology is to create an environment where every learner will have a series of resources and teachers in different discipline expertise and in different locations, with a teacher/mentor to help the student to pursue some areas in depth. This is currently too expensive. Technology can facilitate motivation during the learning process. Though it is not advocated replacing the human teachers with the technology but future technology must live in a symbiotic relationship amongst teachers, students, parents and society at large. Learning vision 2020 focuses on creating learning environments that facilitate communication and collaboration. Technology networks kids together in groups to learn and practice their combined skills. This work critically reviews the traditional Teacher Directed Learning with Modern Technology aided Teacher Directed Learning. An experimental design was followed with two sections: Control group and treatment group. Treatment group was provided with technology aid. At the end of semester, tests showed that treatment group students outperformed students of control group.
\end{abstract}

Keywords: Information Technology; experimental study; Teacher Directed Learning, Self Directed Learning 